\title{
Status of Ocular Complications in Type 2 Diabetes and Relationship Between Other Comorbidities
}

\author{
Jishu Deb Nath ${ }^{{ }^{*}}$ \\ Mozammel Hogue Sharifi ${ }^{2}$
}

'Department of Medicine

Chattagram Maa-O-Shishu Hospital Medical College Chittagong, Bangladesh.

${ }^{2}$ Department of Ophthalmology

Chattagram Maa-O-Shishu Hospital Medical College Chittagong, Bangladesh.
*Correspondence to:

\section{Dr. Jishu Deb Nath}

Assistant Professor

Department of Medicine

Chattagram Maa-O-Shishu Hospital Medical College

Chittagong, Bangladesh.

Mobile: +8801716405056

Email: jishudebnath2007@gmail.com

\begin{abstract}
Introduction : Diabetes Mellitus is a multifactorial disease, associated with a number of micro vascular (Retinopathy, Neuropathy and Nephropathy) and macro vascular (Ischemic Heart Disease, Cerebrovascular Disease and Peripheral Vascular Diseases) complications. Duration of diabetes, current smoking and presence of co morbidities such as HTN, IHD all are significantly associated with the ocular complications in this study. Objective: The purpose of the study is to see the glycaemic status and co morbidities influencing the ocular complications. Methods: The patients for the study were randomly recruited from the Eye outpatient clinics in Chattagram Maa Shishu-O-General Hospital, Chittagong, Bangladesh, from July 2014 to October 2014. Risk factors of DR like age, sex, duration of diabetes and hypertension, IHD, smoking status were evaluated. Results: The study showed that 53 are male and 47 are female. Maximum age is 85 and minimum age is studied at 28. Cataract was the predominant complications presented our study. $22 \%$ patient had unilateral and 20\% had bilateral cataract. 29\% had retinopathy. Mean FPG , PPG \& HBA1c levels in unilateral cataract were $7.0 \mathrm{mmol} / \mathrm{L}, 8.9 \mathrm{mmol} / \mathrm{L}$ and 7.03 $\mathrm{mmol} / \mathrm{L}$ in comparative to retinopathy group was $8.4 \mathrm{mmol} / \mathrm{L}, 10.6 \mathrm{mmol} / \mathrm{L}$ and 8.6 $\mathrm{mmol} / \mathrm{L}$ respectively. Major complications are retinopathy are found in $26 \%$ hypertensive and 24\% IHD patients, prevalence of Diabetic retinopathy is $6.9 \%$ after 5 years onset of DM and 73.9\% after 15 years of diabetes. Conclusion : Prevalence of Diabetic ocular complications is high in our country, Ocular complications increases proportionately to duration and presence of co morbidities. Tight control of DM and periodic eye examination can prevent complications.
\end{abstract}

Key words: Posterior subcapsular cataract; Diabetic retinopathy; Ischemic heart diseases.

\section{INTRODUCTION}

Diabetes mellitus is currently the commonest endocrine disorder, affecting nearly $6 \%$ of the world's population ${ }^{1}$. According to recent estimates by the International Diabetes Federation, the number of patients with diabetes will increase by $55 \%$ to nearly 600 million by year $2035^{2}$.

Data from prospective and cross-sectional studies consistently point to the fact that diabetic patients are more likely to develop micro- as well as macro-vascular conditions $^{3-4}$. About $50 \%$ of the subjects of UKPDS had substantial macro- or microvascular abnormalities at the time of T2 DM diagnosis ${ }^{5}$.

About $50-80 \%$ of all individuals with diabetes die of cardiovascular disease, with cerebrovascular disease, and kidney failure also among the leading causes of death ${ }^{6}$.

Diabetic retinopathy caused by complications of diabetes mellitus and is the fifthleading cause of global blindness. It is an ocular manifestation of systemic disease which affects up to $80 \%$ of all patients who have had diabetes ${ }^{7}$. 
While occurrence of diabetic retinopathy cannot be prevented, early detection and management of the disease can minimize its sight-threatening complications.

Current treatment modalities are effective in preventing 98\% of vision loss, if treatment is provided at the appropriate time.There is additional evidence that the risk of cataract increases with increasing diabetes duration and severity of hyperglycemia ${ }^{8,9}$.

Deposition of advanced glycation end products in the lens has been postulated as one possible pathogenic mechanism for diabetic cataract ${ }^{10}$.

The surge in diabetes in low-resource settings is partly attributed to the insidious nature of the condition, with many people remaining undiagnosed until complications such as vision loss and renal disease manifest.

Consequently, large proportions of people remain undiagnosed or fall within pre-diabetes categories which predispose them to progressing to diabetes ${ }^{11}$.

\section{MATERIAL AND METHODS}

This was a prospective questionnaire based study. The patients for the study were purposively selected from the Eye outpatient clinics in Chattagram Maa Shishu-O-General Hospital, Chittagong, Bangladesh, from July 2014 to Octobor 2014. Subjects were chosen who were more than 16 years old $\&$ who were able to understand clearly the instructions of the survey. All the patients were answered voluntarily and confidently against the administered pre-tested questionnaires. The study was conducted on 100 diabetics patients presented with eye complaints. The patients were informed about the study, and written consent was obtained from them. Confidentiality of the patient was maintained. All questionnaires were administered and collected by the same person. The data was entered using an excel sheet and analyzed using Statistical Package for Social Sciences (SPSS software, version 22).

The frequency of ocular complications, cardiovascular diseases, and hypertension were assessed in these patients. The diagnosis of diabetes is confirmed by fasting plasma glucose, measured from a venous sample after an overnight fast. Ophthalmologists examined all these patients. Vision of each eye was noted with the best possible correction. Snellen's projection chart was used for this purpose. The pupils were dilated by instilling one drop of $1.0 \%$ tropicamide, and examined by fundoscopy and all retinopathic changes are noted.

\section{RESULTS}

\section{Characteristics of the study subjects}

A total of 100 patients were included in the study. From 100 patients, 53 are male and 47 are female. Maximum age is 85 and minimum age is studied at 28, mean age is 57.9. Maximum duration of diabetes presented complications after 24 years and minimum duration after diagnosis is 1 year and mean duration is 7.3 years (Table $1,2,3,4)$.

\section{Glycemic Control}

The mean Fasting Blood Glucose (FBG) levels of patients measured were $7.38 \pm 0.97 \mathrm{mmol} / \mathrm{L}$ in patient with regular exercise groups $(\mathrm{n}=52)$ and $7.82 \pm 1.02 \mathrm{mmol} / \mathrm{L},(\mathrm{n}=48)$ who doesn't undergoes regular exercise. Mean Post Prandial Glucose (PPG) level found $9.19 \pm 1.2 \mathrm{mmol} / \mathrm{L}$ in patient with regular exercise groups $(\mathrm{n}=52)$ and $9.79 \pm 1.27 \mathrm{mmol} / \mathrm{L}$ in patients who doesn't exercise regularly. Mean HBA1c was $7.43 \pm .80$ in exercise group and $7.89 \pm 1.03$ in patient with non exercise group. The mean FBG and PPG values increased significantly with the duration of diabetes. In compliant group $(\mathrm{n}=83) \mathrm{FPG}$ was found $7.4 \mathrm{mmol} / \mathrm{L}$, PPG was $9.2 \mathrm{mmol} / \mathrm{L}$ and HBA1c was 7.4 in comparative to non compliant group $(n=17)$ FPG was $8.2 \mathrm{mmol} / \mathrm{L}$ PPG was $10.2 \mathrm{mmol} / \mathrm{L}$ and HBA1c was 8.5 respectively (Table $5,6,7$ ).

Cataract was the predominant complications presented our study. $22 \%$ patient had unilateral and $20 \%$ had bilateral cataract. $29 \%$ had retinopathy and rest were refractive error. Mean FPG , PPG \& HBA1c levels in unilateral cataract were $7.0 \mathrm{mmol} / \mathrm{L}, 8.9 \mathrm{mmol} / \mathrm{L}$ and $7.03 \mathrm{mmol} / \mathrm{L}$ in comparative to retinopathy group was $8.4 \mathrm{mmol} / \mathrm{L}, 10.6 \mathrm{mmol} / \mathrm{L}$ and 8.6 $\mathrm{mmol} / \mathrm{L}$ respectively. In our study 72 patients were found hypertensive and those who had HTN, mean FPG , PPG \& HBA1c levels were $7.6 \mathrm{mmol} / \mathrm{L}, 9.5 \mathrm{mmol} / \mathrm{L}$ and $7.6 \mathrm{mmol} / \mathrm{L}$ in comparative to normotensive group were $7.3 \mathrm{mmol} / \mathrm{L}, 9.2$ $\mathrm{mmol} / \mathrm{L}$ and $7.4 \mathrm{mmol} / \mathrm{L}$ respectively. $55 \%(\mathrm{n}=55)$ patient had association of IHD and mean FPG, PPG \& HBA1c levels were 7.8, 9.8 and 9.8 in this groups comparative to 7.2, 9.0 and 7.3 in patients who had no IHD.

Major complications is retinopathy are found in $26 \%$ hypertensive and 24\% IHD patients. Maximum 8 patients developed retinopathy after 15 years of diabetes onset.Only 2 patients was found retinopathy just after 5 years of diabetes comparative with 7 patients presented with unilateral and 6 patients with bilateral cataract (Table 8).

Table 1: Baseline characteristics of study populations $(n=100)$

\begin{tabular}{lrrrr} 
& Minimum & Maximum & Mean & Std. Deviation \\
Age (Years) & 28 & 85 & 57.97 & 11.934 \\
Duration (Years) & 1 & 24 & 8.34 & 5.373 \\
BMI & 14.6 & 42.8 & 26.864 & 6.5786 \\
Fasting plasma glucose (mmol/L) & 5.30 & 9.60 & 7.5710 & 1.01507 \\
Post prandial blood glucose (mmol/L) & 7.30 & 14.20 & 9.4470 & 1.29922 \\
HbA1C level (\%) & 6.20 & 10.70 & 7.6250 & .93034 \\
\hline
\end{tabular}

Table 2 : Co-morbidity status in relation to age group

\begin{tabular}{lcr} 
Age Grouping & IHD & HTN \\
$<30$ Years & 0 & 1 \\
$30-50$ Years & 7 & 16 \\
50 -70 Years & 38 & 46 \\
$>70$ Years & 10 & 9 \\
Total & 55 & 72 \\
\hline
\end{tabular}


Table 3 : Distribution of patients according to drug intake

\begin{tabular}{lcc} 
Drug & Frequency & Percent \\
Oral & 51 & 51.0 \\
Insulin & 25 & 25.0 \\
Oral + Insulin & 22 & 22.0 \\
None & 2 & 2.0 \\
Total & 100 & 100.0 \\
\hline
\end{tabular}

Table 4 : Distribution of patient according to smoking status

\begin{tabular}{lccccccc} 
& & \multicolumn{8}{c}{ Complications } \\
& $\begin{array}{c}\text { Unilateral } \\
\text { cataract }\end{array}$ & $\begin{array}{c}\text { Bilateral } \\
\text { cataract }\end{array}$ & PSC* & Retinopathy & $\begin{array}{c}\text { Refractive } \\
\text { error }\end{array}$ & Total \\
Smoking & Yes & 4 & 8 & 2 & 11 & 6 & 31 \\
& No & 18 & 12 & 5 & 18 & 16 & 69 \\
Total & & 22 & 20 & 7 & 29 & 22 & 100 \\
\hline
\end{tabular}

(*PSC : Posterior Subcapsular Cataract)

Table 5: Relationship between glycaemic status and exercise group

\begin{tabular}{lrrrr} 
Exercise & $\begin{array}{r}\text { Fasting plasma } \\
\text { glucose (mmo//L) }\end{array}$ & $\begin{array}{r}\text { Post prandial } \\
\text { blood glucose (mmol/L) }\end{array}$ & $\begin{array}{c}\text { HbA1C level } \\
(\%)\end{array}$ \\
Yes & Mean & $7.38 \pm .97$ & $9.19 \pm 1.26$ & $7.43 \pm .80$ \\
No & Mean & $7.82 \pm 1.02$ & $9.79 \pm 1.27$ & $7.89 \pm 1.01$ \\
Total & Mean & $7.57 \pm 1.01$ & $9.44 \pm 1.29$ & $7.62 \pm .93$ \\
\hline
\end{tabular}

Table 6 : Glycaemic status according to age group

\begin{tabular}{|c|c|c|c|c|c|}
\hline & & $\mathbf{N}$ & $\begin{array}{c}\text { Mean } \\
(\mathrm{mmol} / \mathrm{L})\end{array}$ & Std. Deviation & $p$ value \\
\hline \multirow{5}{*}{$\begin{array}{l}\text { Post prandial } \\
\text { blood glucose }\end{array}$} & $<30$ Years & 2 & 82000 & 14142 & \multirow{5}{*}{0.001} \\
\hline & $30-50$ Years & 32 & 9.1094 & 1.06872 & \\
\hline & $50-70$ Years & 54 & 9.4000 & 1.25908 & \\
\hline & $>70$ Years & 12 & 10.7667 & 1.34457 & \\
\hline & Total & 100 & 9.4470 & 1.29922 & \\
\hline \multicolumn{6}{|c|}{ Fasting plasma } \\
\hline \multirow[t]{5}{*}{ glucose } & $<30$ Years & 2 & 7.2500 & .07071 & \multirow{5}{*}{0.0001} \\
\hline & $30-50$ Years & 32 & 7.1531 & 1.00899 & \\
\hline & $50-70$ Years & 54 & 7.6037 & .89737 & \\
\hline & $>70$ Years & 12 & 8.5917 & .92487 & \\
\hline & Total & 100 & 7.5710 & 1.01507 & \\
\hline
\end{tabular}

Table 7 : Glycaemic status in ocular complications

\begin{tabular}{llrrr} 
Complications & & $\begin{array}{r}\text { Fasting plasma } \\
\text { glucose } \\
\text { (mmol/L) }\end{array}$ & $\begin{array}{r}\text { Post prandial } \\
\text { blood glucose } \\
\text { (mmol/L) }\end{array}$ & $\begin{array}{c}\text { HbA1C level } \\
(\%)\end{array}$ \\
Unilateral cataract & Mean & $7.09 \pm .74$ & $8.92 \pm .90$ & $7.03 \pm .46$ \\
Bilateral cataract & Mean & $7.56 \pm .79$ & $9.32 \pm 1.32$ & $7.41 \pm .70$ \\
PSC & Mean & $7.60 \pm .61$ & $9.15 \pm .73$ & $7.55 \pm .52$ \\
Retinopathy & Mean & $8.49 \pm .84$ & $10.61 \pm 1.17$ & $8.61 \pm .94$ \\
Refractive error & Mean & $6.83 \pm .83$ & $8.61 \pm .78$ & $7.12 \pm .31$ \\
Total & Mean & $7.57 \pm 1.01$ & $9.44 \pm 1.29$ & $7.62 \pm .93$ \\
\hline
\end{tabular}

Table 8 : Relationship between complications and other co-morbidities

\begin{tabular}{lrc} 
Complications & IHD & HTN \\
Unilateral cataract & 10 & 14 \\
Bilateral cataract & 12 & 17 \\
PSC & 2 & 4 \\
Retinopathy & 24 & 26 \\
Refractive error & 7 & 11 \\
Total & 55 & 72 \\
\hline
\end{tabular}

\section{DISCUSSION}

Diabetes Mellitus is a multifactorial disease, associated with a number of microvascular (Retinopathy, Neuropathy and Nephropathy) and macrovascular (Ischemic heart disease, Cerebrovascular disease and Peripheral vascular diseases) complications $^{12}$.

Type 2 DM is likely to remain undiagnosed for many years. The gap between the onset of the disease and clinical diagnosis of diabetes leads to the development of these chronic complications. Duration of diabetes, current smoking and presence of diabetes peripheral neuropathy all were significantly associated with the prevalence of DR in the present study population.

Duration of diabetes is a well known risk factor for DR and most other complications of diabetes ${ }^{13}$. The relationship between smoking and DR is controversial, where several studies have shown no relationship between smoking and longterm incidence, progression of $\mathrm{DR}^{14,15,16}$.

Large prospective studies of both type 1 and type 2 diabetics have shown that a tight control of glycemia reduces the occurrence of DR and other micro vascular complications compared to diabetics on a conventional therapy (The Diabetes Control and Complications Trial Research Group 1993, United Kingdom Prospective Diabetes Study (UKPDS) Group 1998 The prevalence of cataract was higher in those with a longer duration of diabetes and known diabetes, suggesting a more prolonged influence of biochemical cataractogenic stimuli (Hyperglycemia). However, the pathways by which hyperglycemia leads to cataract are still unknown but they probably involve a modification of the lens proteins leading to AGE formation or modification of the ATPase pumps, leading to osmotic stress, or both ${ }^{17}$.

The Blue Mountains Eye Study showed that an impaired fasting glucose, in the absence of clinical diabetes, was also a risk factor for the development of cortical cataract ${ }^{18}$. Both the Framingham eye study and National Health and Nutrition Examination Survey14 reported a positive association between diabetics and cataract prevalence only in those younger than 65 years of age. At older ages the association was not significant in the Framingham eye study 15 and became less significant in NHNES $^{19}$.

The prevalence of DR has been documented to be higher in Type 1 DM compared to Type 2 DM. We had information on patients currently being treated with insulin and/or by other treatment modalities. We found that the rate of DR among patients using insulin was significantly higher compared to those using other medications. But long duration of DM and poor glycemic control could have prompted physicians to treat these cases with insulin. Thus association of type of treatment with DR could have been confounded by the duration and poor glycemic control in our study. 
The study had few limitations as patients were selected from outdoor visiting patients in eye department. Patients were selected only type 2 . In our institute only less severe patients attended here as there is large number of patient attending in nearby specialized eye hospital. In our study bilateral cataract was found on 8 patients with active smoker and. Retinopathy was found on 11 patients. Results is comparatively less than nonsmoker due to large number of female patients. Result of our study on diabetics with cataract somewhat consistent with Barbados eye study as our study also shows positive influence below 60 years of age on cataract.

Those who are hypertensive, 26 patients had retinopathy (36.1\%). Only 3 retinopathy patients are found in non hypertensive group.

In one eye hospital based study of 350 patients in Sana, Yemen, prevalence of Diabetic retinopathy is $18.6 \%$ after 5 years onset of DM and $87 \%$ after 15 years of diabetes ${ }^{20}$. In our study it is $6.9 \%$ and $73.9 \%$ respectively, so this is consistent with that study.
Diabetes treated with Insulin in our study is $43.5 \%$ in retinopathy group and $48.5 \%$ is managed by both oral and insulin in same group, but in Yemen study it is comparatively $73.9 \%$ and $43.5 \%$, provided by severe cases enrolled in that hospital.

\section{CONCLUSION}

Prevalence of Diabetic ocular complications is high in our country, as early diabetes detection, prolonged durations, drug compliance, exercise all are closely related to eye complications .Other co morbidities such as HTN ,IHD all are proportionately related with cataract and retinopathy, So Early visit to ophthalmologists as well as control of co morbidities and DM should be emphasized.

\section{DISCLOSURE}

Both the authors declared no competing interest. 


\section{REFERENCES}

1. Adeghate E, Schattner P, Dunn E. An update on the etiology and epidemiology of diabetes mellitus. Ann NY Acad Sci. 2006; 1084:1-29.

2. International Diabetes Federation: Diabetes Atlas. Brussels: International Diabetes Federation, Editor. 2013.

3. Lee ET, Keen H, Bennett PH, Fuller JH, Lu M. Follow-up of the WHO Multinational Study of Vascular Disease in Diabetes: General description and morbidity. Diabetologia. 2001; 44(Suppl (2)):S3-13.

4. LeRoith D, Fonseca V, Vinik A: Metabolic memory in diabetes-focus on insulin. Diabetes Metab Res Rev. 2005; 21(2):85-90.

5. Turner RC, Holman RR. Lessons from UK prospective diabetes study. Diabetes Res Clin Pract. 1995; 28(Suppl(7)):S151-157.

6. Linda SG, William HH, Smith PJ. Mortality in Non-Insulin-Dependent Diabetes[A]. National Diabetes Data Group. Diabetes in America. Bethesda 2nd edition. 1995. NIH Publication NO.9521468

7. Kertes PJ, Johnson TM. (2007). Evidence Based Eye Care. Philadelphia, PA: Lippincott Williams \& Wilkins. ISBN 0-7817-6964-7.

8. Ferris FL. How effective are treatments for diabetic retinopathy? JAMA. 1993; 269:1290-1291.

9. Negahban K, Chern K: Cataracts associated with systemic disorders and syndromes. Curr Opin Ophthalmol. 2002;13:419-422.

10. Pirie A. Epidemiological and biochemical studies of cataract and diabetes. Invest Ophthalmol. 1965;4:629-637.

11. IDF (2012) International Diabetes Atlas Fifth edition.

12. Rahman S, Rahman T, Ismail AA, Rashid AR. Diabetes-associated macrovasculopathy: Pathophysiology and pathogenesis. Diabetes Obes Metab. 2007;9(6):767-180

13. Nirmalan PK, Robin AL, Katz J et al. Risk factors for age related cataract in a rural population of southern India: The Aravind Comprehensive Eye Study. Br J Ophthalmol. 2004;88:989-994.

14. Wang JJ. Global prevalence and major risk factors of diabetic retinopathy. Diabetes Care. 2012; 35(3):556-564.

15. Moss SE, Klein R, Klein BE. Cigarette smoking and ten-year progression of diabetic retinopathy. Ophthalmology. 1996; 103(9):1438-1442.

16. Moss SE, Klein R, Klein BE. Association of cigarette smoking with diabetic retinopathy. Diabetes Care. 1991; 14(2):119-126.

17. Chan AW, Ho YS, Chung SK, Chung SS. Synergistic effect of osmotic and oxidative stress in slow-developing cataract formation. Exp Eye Res. 2008;87(5):454-461.

18. Rowe NG, Mitchell PG, Cumming RG, Wans JJ. Diabetes, fasting blood glucose and age-related cataract: The Blue Mountains Eye Study. Ophthalmic Epidemiol. 2000;7:103-114.

19. Hiller R, Robert D Sperduto, Ederer F. Epidemiologic associations with cataract in the 1971-1972 National Health and Nutrition Examination Survey. Am J Epidemiol. 1989;118(2):239-249.

20. Mahfouth A Bamashmus, Abdallah A Gunaid, and Rajiv B Khandekar. Diabetic retinopathy, visual impairment and ocular status among patients with diabetes mellitus in Yemen: A hospital-based study.Indian J Ophthalmol. 2009; 57(4): 293-298. 